\title{
Why are Inappropriate Barrier-free Acoustic Designs for Visually Impaired Persons Provided?
}

\author{
Koji Nagahata \\ Fukushima University
}

\begin{abstract}
In Japan, many sounds designed for the visually handicapped are not only useless, but also create noise for the impaired and non-impaired people alike. Interview surveys with visually handicapped people were analyzed to reveal why inappropriate barrier-free acoustic designs have been provided for them. Responses from participants were divided into three categories: (1) mistaken needs-assessments, (2) poor technical knowledge of the visually impaired and (3) problems of power/political relationships. Furthermore, the responses of almost all the participants seemed to apply as well to other kinds of barrier-free designs, in spite of the fact that the topic of this survey focused only on acoustic designs. The results suggest that we must examine social as well as technical and psychological issues when we plan barrier-free designs. $J$ Physiol Anthropol Appl Human Sci 24(1): 45-49, 2005 http://www.jstage.jst.go.jp/browse/jpa
\end{abstract}

Keywords: barrier-free designs, the visually impaired, needs-assessments, technical knowledge, power/political relationships

\section{Introduction}

Making barrier-free urban environments for the handicapped is an important problem that should be addressed. For this purpose, much research has been conducted and many designs developed.

In the field of acoustic design, the use of sounds for the orientation and mobility of the visually impaired has been investigated (Ota et al., 1996, 1998; Nagahata, 1998, 2000; Iwamiya et al., 2004). In addition, various kinds of sounds have been designed. Moreover, guidelines for supporting these impaired people by using sounds (The Policy Bureau MLIT ed., 2002) were drawn up in 2002, as a result of the enforcement of the traffic barrier-free law in 2000. In this situation, the amount and varieties of sounds for the visually impaired have been increasing, especially in urban areas.

It goes without saying that well-designed sounds can be a great help to the visually handicapped. However, inappropriate sounds are not only useless for the visually impaired people, but also create noise for the impaired and non-impaired people alike. Unfortunately in Japan, as Nagahata pointed out (Nagahata, 2004), many inappropriate sounds have been provided for the visually handicapped. These sounds can be classified into six typical categories: (1) sound level is too low, (2) sound reverberates too much, (3) similar sounds are set up in the same neighborhood, (4) inappropriate announcements are made, (5) sounds are provided at inappropriate places or times, and (6) information about the sounds, for example where new sounds have been provided or what new sounds mean, is not distributed to the visually-impaired people. Furthermore, these kinds of inappropriate sounds tend to increase with the increase of sounds for the visually handicapped.

In spite of much research that has been conducted and many sounds that have been developed, why are inappropriate barrier-free acoustic designs for visually impaired persons provided? In making effective barrier-free acoustic environments, this is a problem that we cannot ignore.

In this paper, interview surveys with the visually handicapped people are analyzed to reveal one aspect of this problem.

\section{Methods}

The author has been researching how the visually-impaired people use sounds (Nagahata, 1998, 2000, 2004). For the research, interview surveys were carried out with more than fifty visually-impaired people. The participants included both totally blind and low-vision people, and both the innate handicapped and late handicapped. The surveys were carried out in many different districts including Fukuoka, Kobe, Tokyo, Fukushima, and Hokkaido.

The interviews were originally conducted for several different studies. Therefore, in some cases, the sounds around the participants were the main topic of the surveys, while in other cases, a specific sound was the focus of the investigation. In the last part of all the interview surveys, however, participants were required to comment freely on the acoustic 
Table 1 Categories indicated in each interview survey

\begin{tabular}{|c|c|c|c|c|c|c|}
\hline & \multicolumn{2}{|c|}{ (1) Mistaken needs-assessments } & \multirow[b]{2}{*}{$\begin{array}{l}\text { (2) Poor technical } \\
\text { knowledge of the } \\
\text { visually impaired }\end{array}$} & \multicolumn{2}{|c|}{$\begin{array}{l}\text { (3) Problems of power/political } \\
\text { relationships }\end{array}$} & \multirow[b]{2}{*}{ Exceptions } \\
\hline & $\begin{array}{l}\text { Administrators and/or } \\
\text { maintainers tend } \\
\text { not to listen to the } \\
\text { opinions of the } \\
\text { visually impaired }\end{array}$ & $\begin{array}{l}\text { The method of } \\
\text { consultation is } \\
\text { inappropriate }\end{array}$ & & $\begin{array}{c}\text { Disparities in } \\
\text { relationships between } \\
\text { the visually impaired } \\
\text { and the } \\
\text { administration }\end{array}$ & $\begin{array}{l}\text { Power/political } \\
\text { problem related to } \\
\text { the associations for } \\
\text { visually impaired } \\
\text { people }\end{array}$ & \\
\hline $\begin{array}{l}\text { Group A } \\
\text { (5 participants) } \\
\text { Group B } \\
\text { (2 participants) } \\
\text { Group C } \\
\text { (2 participants) } \\
\text { a (individual } \\
\text { interview) } \\
\text { b } \\
\mathrm{c} \\
\mathrm{d} \\
\mathrm{e} \\
\mathrm{f} \\
\mathrm{g} \\
\mathrm{h} \\
\mathrm{i} \\
\mathrm{j} \\
\mathrm{k} \\
\mathrm{l} \\
\mathrm{m}\end{array}$ & $\begin{array}{l}* \\
* \\
* \\
* \\
* \\
* \\
* \\
* \\
* \\
* \\
* \\
* \\
* \\
* \\
*\end{array}$ & $\begin{array}{l}* \\
* \\
* \\
*\end{array}$ & * & $\begin{array}{l}* \\
* \\
* \\
* \\
* \\
* \\
*\end{array}$ & $\begin{array}{l}* \\
* \\
* \\
* \\
* \\
* \\
* \\
* \\
* \\
*\end{array}$ & $\begin{array}{l}1 \\
1 \\
1\end{array}$ \\
\hline
\end{tabular}

“*” shows that the response(s) which classified into the corresponding category was pointed out in corresponding survey.

"1" shows that a response which means "poor technical knowledge of the administrators and/or maintainers" was pointed out.

environment of their daily lives. Inappropriate barrier-free acoustic designs were always commented on in this part of the interview surveys. In the surveys which were carried out in 2003 and 2004, if a participant did not point any out during the interview, the researcher asked whether or not sounds that were inappropriate for them existed in their daily environment.

In the interviews carried out in 2003 and 2004, whenever a participant pointed out ineffective sounds, they were asked why they thought such inappropriate sounds were provided. Twenty-two participants, who were divided into three groups for group interviews or participated in thirteen one-on-one interviews, were asked this question. These responses were analyzed with some responses from interviews conducted before 2003 being used collaterally.

In some cases interview surveys were carried out one-onone, and in other cases group interviews were conducted. There was a tendency towards a greater variety of responses in group interviews than in one-on-one interviews. Also, as mentioned above, the purpose of each interview was different. Therefore, the exact frequencies of each response seem not to be so important. For this reason, the substance of each response is discussed, but the frequencies of each response are not analyzed.

\section{Results and Discussion}

Responses with respect to why the visually impaired think inappropriate sounds have been provided are divided broadly into three categories: (1) mistaken needs-assessments, (2) the visually impaired have only poor technical knowledge and (3) problems of power/political relationships. Table 1 shows the categories that were indicated in the interview surveys carried out in 2003 and 2004. In what follows, the responses are discussed in detail according to these three categories.

\section{(1) Mistaken needs-assessments}

The most typical response in this category is that administrators and/or maintainers tend not to listen to the opinions of the visually impaired. According to one participant, "There are a lot of sounds which persons without visual disability who never hear the opinions of the visually handicapped and never understand their actual needs seem to believe necessary for the visually impaired. These sounds seem to be considered only in their mind's eye." In other words, there are many sounds that would not have been provided if administrators and/or maintainers had previously asked the opinions of the visually impaired. Many participants suggested that this kind of inappropriate barrier-free design is found not only in the case of acoustic design, but in many other instances 
of barrier-free designs for the visually impaired.

Another participant gave the following example. She heard that there was a plan for a certain sound system to be provided in her neighborhood. From her experience, she thought that the sound would not be efficient at the designated place. Therefore, she advised the maintainers that the sound system which they planned to provide would be inefficient and another sound system would be better for the particular location. However, the maintainers ignored her advice, and the sound system was provided as arranged. Not surprisingly, it is really inappropriate for the location.

In another example: a subject was invited to a hearing about a new facility, and was also asked to bring along some visually handicapped people, so he asked the maintainer of a facility what type of visually handicapped they wanted. He meant there are many types of visually handicapped, such as totally blind or low-vision people, whose handicap might be either innate or acquired later in life; the opinions of people with different types of visual impairment are sometimes different from each other. However, the maintainer answered this question from another point of view. The answer from the maintainer was that he wanted those visually handicapped who would not provide a critical evaluation. This answer seems to suggest that the maintainer did not really want to hear the opinions of the visually handicapped, and just wanted to claim that he had heard from the parties concerned.

Regarding these circumstance, some of the subjects said that some administrators and/or maintainers seems to think that the act of providing something for the handicapped itself becomes an indulgence and therefore they think they do not need to ask about the needs of the handicapped.

Another type of problem is that too much confidence is placed in manuals and guidelines provided by authorities. Before new sounds are set up in certain locations, maintainers always check the manuals and/or guidelines. Basically, this action itself is correct. But some tend to think that it is enough if they do so, and do not worry about the things that are not specifically listed; even basic problems such as whether or not the sounds are really suitable for the locations. This type of maintainer rarely talks with visually impaired people directly, so they do not know their real needs. In spite of this, they often decide to set up sounds after only checking the manuals and/or the guidelines. In this process of decision-making, opinions of the visually handicapped are not considered.

According to some subjects, when the inappropriateness of a sound was pointed out to this type of maintainer, they always answered that they obeyed the manuals and/or the guidelines conscientiously, so there ought not to be a problem.

As just described, many participants felt that their opinions were not adequately heard, and this caused mistaken needsassessments. Regarding this problem, several participants pointed out that consultation opportunities with administrators and/or maintainers have been increasing lately.

Even if consultations with the visually impaired are carried out, if the method of consultation is inappropriate, then mistaken needs-assessments will also occur.

In the present circumstances, when administrators call visually impaired people to hearings, they always invite a limited type of person, for example people who are members of a large association for the visually impaired and/or staff of schools for blind. So, even if the topics of the hearings are about particular locations, the visually impaired people who are not familiar with the locations are invited, instead of those people who are directly concerned. It is extremely difficult for someone who is unfamiliar with a certain place to point out its particular problems. Therefore, in such cases, those invited can only offer general advice on the matter and consequently, actual demands are not conveyed to the administrators.

The visually impaired also understand that the people from whom administrators ask are limited. Participants who were often invited to hearings felt that their opinions were always regarded as representative of the entire population of the visually-impaired people, not as their own individual voices. Therefore, they were very afraid that sounds which are required by other visually impaired people are not set up when they give, as their own opinion, the advice that the sounds are not needed. For this reason, many visually-impaired people who have been invited to hearings said that they could never say at the hearings that the sounds are not needed.

A similar problem is found in the case of questionnaire surveys. According to one participant, because he could not deduce to what kinds of persons the questionnaires were distributed to and what kind of people would reply to them, he was always afraid of how these response would be treated. He meant that if only biased persons replied to the questionnaire or, even worse, only biased persons were selected to complete the questionnaire, the results would be biased. However, sometimes these kinds of responses are regarded as representative of all visually impaired people. In these circumstances, it is possible that sounds that some visually impaired people would like to have provided are not set up if many of the biased people reply that those sounds are useless. Therefore, he did not ever answer that a certain sound is useless. Similar responses were given by several participants. For the same reason, some participants said that they did not answer questionnaire surveys except in those cases where they knew the researchers well and thought them credible in distributing the questionnaires.

In this way, many subjects thought the mistaken needsassessments were carried out, regardless of whether their opinions were heard or not.

\section{(2) The visually impaired have only poor technical knowledge}

Many subjects pointed out that they did not understand what is possible and what is impossible with the current technology, and some subjects thought this caused some problems.

A typical response from the participants was that they did not understand what is possible and what is impossible for the current technology. Consequently when a certain sound system 
was hard to use, they could not judge whether the system could be improved using the current technology and could also not imagine an alternative proposal. In this situation, they could not point out the problem adequately, and they could only say the system was hard to use in some way. Hence, they thought they had no choice but to accept the situation and keep on using the system.

Another typical response with respect to the evaluation of a newly provided sound showed a lack of understanding of the best current technology and what is possible: they could not imagine what kinds of sounds were the most effective for them because of this lack of understanding. This means that they could not set evaluation standards by themselves. Therefore, they thought they could only say that the newly provided sound could be useable, except in cases where the sound was definitely useless. According to one participant, there was no doubt that all sounds, unless definitely useless, were "usable" in some way, apart from whether they were actually used or not. The respondent continued that there was the possibility that a certain sound could be improved if it kept being used, but this possibility disappeared if the sound was not used at all. For this reason, he thought sounds provided for the visually handicapped should be used continuously, even if the sounds are inefficient.

It follows from what has been said, that shortage of technical knowledge seems to prevent people from making genuine evaluations.

Regarding this shortage of technical knowledge, several participants said that an administrative office is the only channel for making demands related to barrier-free designs, and they have never met designers or engineers directly. So they have never heard any technical explanation from experts. They thought this is one of the reasons why they did not understand the current technology for barrier-free designs.

It seems reasonable to suppose that the fact that the participants had never met designers or engineers also means there are designers and engineers who do not know the real opinions of the visually impaired people and may not understand that they do not always evaluate barrier-free designs as the engineers and designers think they do. This situation may lead to mistaken needs-assessments.

This type of problem might almost disappear if designers and/or engineers suitably inform the visually impaired about technical issues. Recently in the field of medical care, the quality of informed consent has become a problem. It can be said that designers and engineers are in a similar position to medical staff in that they are required to make their technical knowledge understandable and appropriate for the parties concerned.

\section{(3) Problems of power/political relationships}

A typical response in this category is that the visually impaired found it difficult to make demands to meet their needs because they tended to be reserved with the administration to which they are always indebted. Regarding this type of opinion, some older subjects commented that older visually-impaired persons especially tend to be reserved and not to express their true feelings, because they have been taught that visually-impaired people must not make a fuss because they need help from the people around them.

Some participants felt that disparities in power/political relationships between them and the administration are much wider. For example, a participant said that when he was required to evaluate new products or services for the visually impaired, he felt he could not give an honest but poor evaluation because there was the possibility that his opinions would be ignored by administrators in the future. This kind of anxiety was noted by various participants. A previous case in which the maintainer of a certain facility wanted a participant to introduce a visually handicapped person who was unlikely to give a poor evaluation suggests that this kind of anxiety is not the result of groundless apprehensions.

Furthermore, some subjects said that many visually handicapped people feared that the administration would disadvantage them next time if the administration felt they made a fuss or their assertions were too strong. Therefore, they tended not to proclaim too strongly to the administration.

In these situations where the visually impaired feel disparity between themselves and the administration, it is reasonable to suppose that they do not express their true feelings. It means that it is very difficult for the administration to hear the real needs of the visually impaired in these situations. This must be one of the reasons why mistaken needs-assessments are carried out.

Another type of the problem with the power/political relationship is that some associations for the visually impaired people adopt a two step strategy of which the first is to make environments better than in the current situation, even if only a little. To achieve this they demand only those barrier-free designs that they know the administration will readily agree to provide, even if those designs are only slightly better than nothing. After the better environments are provided, they then demand the barrier-free designs that they really want but which will be more difficult to provide. In this way, sounds that are not very useful for the visually impaired might be provided, as the first stage of their strategy.

There is another type of power/political problem related to the associations for visually impaired people. One of the main purposes of organizing these associations is the realization of their demands. Some participants stated that some associations seem to be beginning to believe that the fact that having their requests accepted is the most important factor for their activities: they seem to have an illusion that the fact itself means they have political power, which they think attractive not only to members of their associations but also to the visually impaired people who are thinking of joining an association for the visually impaired because it seems to potentially lead to better environments for them. In this process, these associations begin to think less of the real demands of the visually impaired and tend to request sounds 
which are easy for the maintainer to provide instead of sounds which are really and strongly required by the visually impaired people. In this way, the sounds that are only a little better than nothing are sometimes provided.

Furthermore, several participants pointed out that some associations are connected with companies that develop the barrier-free equipment to secure a loan for their work, and these associations always request the barrier-free equipment made by the companies with whom they are connected, even if they find the equipment hard to use.

These indications suggest that it is impossible to carry out accurate needs-assessments through listening only to the members of the limited number of associations.

\section{Conclusions}

In this paper, interview surveys with the visually handicapped people were analyzed to reveal why they think inappropriate barrier-free acoustic designs have been provided for them, in spite of much research having been conducted and many sounds having been developed.

As a result, the responses from participants have been divided into three categories: (1) mistaken needs-assessments, (2) the poor technical knowledge of the visually impaired and (3) problems of power/political relationships.

This survey focused only on the views of the visually impaired. Therefore, there may be some objections from the administration and/or the maintainers of the facilities. However we must keep in mind that the visually impaired thought that there were these kinds of problems when barrier-free sounds were provided. This means that we must consider not only acoustical problems but also social issues when we design new barrier-free systems.

Furthermore, although the topic of this survey was only acoustic designs for the visually impaired, almost all of the opinions of the visually impaired seemed to apply as well to other kinds of barrier-free designs: indicating that these opinions reflect problems that are not peculiar to just acoustical design. It means that we must examine social as well as technical and psychological issues when we develop barrierfree designs.
Acknowledgements The author expresses his sincere appreciation to all the participants for their cooperation in this study. This research was partially supported by the Ministry of Education, Science, Sports and Culture, Grant-in-Aid for Young Scientists (B), 15700362, 2003-2005.

\section{References}

Iwamiya S, Yamauchi K, Shiraishi K, Takada M (2004) Universal design of auditory signals. Proc ICA 2004: I-427I-430

Nagahata K (1998) A study of how blind people identify a place by using environmental sounds. Proc inter-noise 98 (CD-ROM)

Nagahata K (2000) A study of how visually impaired persons identify a place using environmental sounds. J Acous Soc Jpn: 406-417 [In Japanese]

Nagahata K (2004) Ineffective "barrier-free acoustic design" for visually impaired persons. Proc inter-noise 2004 (CDROM)

Ota A, Tamura A, Kashima N (1996) Visually handicapped pedestrians and sound: Developmental change in the use of auditory information. Acous Soc Am and Proc Jpn 3rd Jt Meet: 489-493

Ota A, Tamura A, Kashima N (1998) The visually handicapped and the sound environment -Visually handicapped pedestrians' psychological structure about the usage of the information for route cognition-. Proc internoise 98 (CD-ROM)

The Policy Bureau, Ministry of Land, Infrastructure and Transport ed. (2002) Guidelines for supporting visually impaired people using sounds. EcoMo Foundation, Tokyo, 19-47 [In Japanese]

Received: September 1, 2004

Accepted: October 13, 2004

Correspondence to: Koji Nagahata, Fukushima University, 1

Kanayagawa, Fukushima 960-1296, Japan

Phone: +81-24-548-5154

Fax: +81-24-548-5154

e-mail: nagahata@ads.fukushima-u.ac.jp 